\title{
ACBSP NEws
}

\section{Letter From the American Chiropractic Board of Sports Physicians President}

\author{
Robert C. Nelson, DC, DACBSP, FICC
}

2017 was a great year for the growth of the American Chiropractic Board of Sports Physicians (ACBSP ${ }^{\circledR}$ ). Last year alone we added 132 new Certified Chiropractic Sports Physicians $\left(\mathrm{CCSP}^{\circledR}\right)$ and 25 new Diplomates of the American Chiropractic Board of Sports Physicians $\left(\right.$ DACBSP $\left.{ }^{\circledR}\right)$. Classes for these certifications are being held all over the country, Portland, Los Angles, Kansas City, Birmingham Alabama, Dallas, Davenport and Boston just to name a few. The certification of Sports Chiropractors is the largest specialized group in Chiropractic, with doctors serving almost every major professional sports organizations and at the United States Olympic Committee (USOC) facilities and at the Olympic Games.

Each year at our Sports Science Symposium, abstracts are presented by our certificants, which add to the body of knowledge about chiropractic. The most recent Symposium was held in Colorado Springs in April. We had over 300 participants registered for the Symposium including DCs, ATCs, DC students and those holding the CSCS designation. One of the abstracts presented was "A Survey of Income Comparison: General Practice and Sports Certified Chiropractors", by Drs. W. Moreau, D. Nabhan, and T. Holder. In this survey they showed that "Sports chiropractors averaged $\$ 103603$ more in collections than the general practitioners". Again showing that this is a testament to the value of the additional training and recognition of the CCSP ${ }^{\circledR}$ and DACBSP ${ }^{\circledR}$ qualifications. This last Symposium our Chairmen, Bill Moreau and Dustin Nabhan organized wonderful speakers from all healthcare professions who brought useful and up to date information to our attendees.

A major development in reference to our certifications was negotiated this year. In a signed letter the American Chiropractic Association (ACA), the American Chiropractic Association-Sports Council (ACA-SC) and the ACBSP ${ }^{\circledR}$ came to an agreement that the only sports certifications that are recognized by these three organizations in the United States are the $\operatorname{CCSP}^{\circledR}$ and the DACBSP ${ }^{\circledR}$. Subsequent to that letter being signed the Medical Director for the USOC also confirmed that only these designations will be considered for service with the USOC.

As we all know concussion is one of the major topics in Sports Medicine. Finally the "Consensus statement on concussion in sport - the $5^{\text {th }}$ international conference on concussion in sport held in Berlin, October 2016" was finally released for publication including the new SCAT5. The ACBSP ${ }^{\circledR}$ having established a concussion training program and registry in concert with DConline will offer this new information in an online class. After taking the class those participants will be placed on the National Registry signifying that they have had a course in the most up to date information on concussion. This course is open to all healthcare providers. To check on the concussion registry or upcoming Symposiums go to our website, www.acbsp.com. Keep in touch by joining us on Facebook at https://www.facebook.com/SportsChiropractors.

I look forward to seeing you in person at our next Symposium which will be held in the San Diego, CA, Gaslamp Quarter, April 12-15, 2018. Save the dates. 